\title{
Empirical study on environmental knowledge and attitudes of Hungarian Geography Teacher students
}

\author{
János, Varjas \\ University of Pécs
}

\begin{abstract}
We have to alter our society for a sustainable future. Education has a crucial role in reaching such aims. There is an increasing importance of environmental education in Hungarian schools as well. As a result of this, there is increasing interest in teacher's and undergraduate teacher's environmental literacy along with their academic knowledge. Despite that, there are very few researches that are conducted on this topic. This study focusing on measuring environmental knowledge, attitudes, and behavior of Geography Teacher students attending the University of Pécs, Hungary. A questionnaire with three segments of questions was designed to assess the environmental competencies. The measurement's findings show that Hungarian teacher candidates find global climate change the most important and far-reaching problem of the world and that labor shortage caused by migration is the most substantial issue of Hungary. The asked students have positive attitude towards the environment but have low level of environmental knowledge and behavior. It is possible that the deficient knowledge about the environmentally conscious lifestyle will complicate the development of environmental literacy of their future pupils.
\end{abstract}

Keywords:

Environmentally Friendly Attitude; Environmental Challenges; Environmental Knowledge; Environmentally Conscious behavior; Geography Teacher Students; Questionnaire 